\title{
REDUCED POSTOPERATIVE BLOOD LOSS AND TRANSFUSION REQUIREMENT AFTER BEATING-HEART CORONARY OPERATIONS: A PROSPECTIVE RANDOMIZED STUDY
}

Raimondo Ascione, MD

Simon Williams, MPhil, BSc

Clinton T. Lloyd, FRCS

Thiagarajamirthy Sundaramoorthi, FRCS

Antonis A. Pitsis, FETCS

Gianni D. Angelini, FRCS
Objective: Coronary artery bypass grafting on the beating heart through median sternotomy is a relatively new treatment, which allows multiple revascularization without the use of cardiopulmonary bypass. A prospective randomized study was designed to investigate the effect of coronary bypass with or without cardiopulmonary bypass on postoperative blood loss and transfusion requirement.

Methods: Two hundred patients with coronary artery disease were prospectively randomized to (1) on-pump treatment with conventional cardiopulmonary bypass and cardioplegic arrest and (2) off-pump treatment on the beating heart. Postoperative blood loss identified as total chest tube drainage, transfusion requirement, and related costs together with hematologic indices and clotting profiles were analyzed.

Results: There was no difference between the groups with respect to preoperative and intraoperative patient variables. The mean ratio of postoperative blood loss and 95\% confidence interval between groups was 1.64 and 1.39 to 1.94 , respectively, suggesting on average a postoperative blood loss 1.6 times higher in the on-pump group compared with the off-pump group. Seventy-seven patients in the off-pump group required no blood transfusion compared with only 48 in the on-pump group $(P<.01)$. Furthermore, less than $5 \%$ of patients in the on-pump group required fresh frozen plasma and platelet transfusion compared with $30 \%$ and $25 \%$, respectively, in the onpump group (both $P<.05$ ). Mean transfusion cost per patient was higher in the on-pump compared with that in the off-pump group ( $\$ 184.8 \pm \$ 35.2$ vs $\$ 21.47 \pm \$ 6.9, P<.01)$.

Conclusions: Coronary artery bypass grafting on the beating heart is associated with a significant reduction in postoperative blood loss, transfusion requirement, and transfusion-related cost when compared with conventional revascularization with cardiopulmonary bypass and cardioplegic arrest. (J Thorac Cardiovasc Surg 2001;121:689-96)
I recent years life-threatening morbidity and mortality after cardiopulmonary bypass (CPB) has been significantly decreased. ${ }^{1-3}$ However, the duration of CPB and its influence on hemostasis, platelet count, and function still contributes to postoperative bleeding. ${ }^{1-5}$

Despite improvements in donor screening methods, ${ }^{6}$ there is still an important risk related to the transfusion

From the Bristol Heart Institute, Bristol Royal Infirmary, Bristol, United Kingdom.

This work was supported by the British Heart Foundation and the Garfield Weston Trust.

Copyright (C) 2001 by The American Association for Thoracic Surgery

$0022-5223 / 2001 \$ 35.00+0 \quad \mathbf{1 2 / 1 / 1 1 2 8 2 3}$

doi:10.1067/mtc.2001.112823 of blood and blood products, such as the transmission of viral infections, the induction of immunologic transfusion reactions, and suppression of the immune system. $^{2}$

Recently, there has been a revival of interest on the use of beating-heart operations for coronary artery bypass grafting $(\mathrm{CABG})$, with the suggestion that this may reduce postoperative blood loss, the need for blood transfusion, and costs. ${ }^{7-11}$ However, this has not been confirmed with a prospective randomized study. Furthermore, there are no data on the influence of beating-heart coronary grafting on postoperative hematologic and hemostatic parameters.

The present prospective randomized study compared postoperative blood loss identified as total chest tube 
drainage and transfusion requirement in patients undergoing $\mathrm{CABG}$ either on the beating heart or with $\mathrm{CPB}$ and cardioplegic arrest.

\section{Methods}

From March 1997 to August 1998, 538 patients underwent first-time CABG under the supervision of a single consultant (G.D.A.). Eligibility for operation was based on the medical history and the most recent angiogram. The investigations reported in the present study are part of a more comprehensive analysis between the 2 groups, which included the evaluation of economic outcome, length of stay, and postoperative morbidity.

Patient selection and randomization. Eligibility to enter the trial was based on the following exclusion criteria: preexisting coagulopathy or other disorders of hemostasis, such as low platelet count, known platelet dysfunction, or history of bleeding tendencies; left ventricular ejection fraction of less than 30\%; recent myocardial infarction $(<1$ month); reoperation; previous stroke or transient ischemic attack; and respiratory or renal impairment. Patients with coronary artery disease involving branches of the circumflex artery distal to the first obtuse marginal branch and posterior branches originating from the left system were also excluded from the study because these were believed to be technically difficult for adequate revascularization at the beginning of our experience with offpump operations. A total of 200 patients who met the eligibility criteria and consented to participate in the trial were individually randomized to undergo myocardial revascularization with either (1) a conventional on-pump operation or (2) an offpump operation on the beating heart. The randomization codes were concealed in numbered, sealed, opaque envelopes. The treatment allocation for a patient was determined by opening the next envelope the evening before the operation.

The study was approved by the United Bristol Healthcare Trust Ethics Committee.

Anesthetic and heparin management. Anesthetic technique was standardized for all patients, as previously reported. ${ }^{11}$ In brief, this consisted of intravenous anesthesia with propofol and remifentanil infusions. Neuromuscular blockade was achieved with pancuronium or vecuronium bromide, and the lungs were ventilated to normocapnia.

In the on-pump group heparin was given at a dose of 300 IU/kg to achieve a target activated clotting time (ACT) of 480 seconds or above before commencement of CPB. In the offpump group, heparin (100 IU/kg) was administered before the start of the first anastomosis to achieve an ACT of 250 to 350 seconds. ${ }^{11}$

\section{Surgical technique}

On-pump group. CPB was instituted by means of ascending aortic cannulation and 2-stage venous cannulation of the right atrium, as previously described. ${ }^{11}$ Nonpulsatile flow was used, and flow rates throughout bypass were $2.4 \mathrm{~L} \cdot \mathrm{m}^{-2}$ - $\min ^{-1}$. Systemic temperature was kept between $34^{\circ} \mathrm{C}$ and $36^{\circ} \mathrm{C}$. Myocardial protection was achieved by using intermittent antegrade hyperkalemic warm blood cardioplegia. ${ }^{12}$

Off-pump group. The method of exposure and stabilization used to perform the anastomosis consisted of the technique pre- viously described by our group. ${ }^{8,13}$ The target vessel was exposed and snared above the anastomotic site by using a 4-0 Prolene suture (Ethicon, Inc, Somerville, NJ) with a soft plastic snugger to prevent coronary injury. An intracoronary shunt (Anastoflo Intravascular Shunt, Research Medical, Inc, Salt Lake City, Utah) was used only in case of relative electrocardiographic or hemodynamic instability or with excessive bleeding during the construction of the distal anastomoses.

Fluid management. In the on-pump group the extracorporeal circuit was primed with $1000 \mathrm{~mL}$ of Hartmann solution, $500 \mathrm{~mL}$ of colloidal plasma volume substitute (Gelofusine; Braun-Milsungen), $0.5 \mathrm{~g} / \mathrm{kg}$ mannitol, and $6000 \mathrm{IU}$ of heparin. During CPB, when additional volume was required, this consisted of Gelofusine plasma volume substitute (hematocrit level, $>22 \%$ ) or red blood cells (hematocrit level < $22 \%$ ). In the off-pump group, intraoperative fluid administration (Gelofusine) was used together with increments of metaraminol $(0.5-1 \mathrm{mg})$ to maintain the mean systemic pressure at $60 \mathrm{~mm} \mathrm{Hg}$ or greater.

Fluid management postoperatively consisted in both groups of $5 \%$ dextrose infused at $1 \mathrm{~mL} \cdot \mathrm{kg}^{-1} \cdot \mathrm{h}^{-1}$, with additional Gelofusine or blood to maintain normovolemia and the hematocrit level at greater than $24 \%$.

Management of postoperative bleeding and related treatment. A minimum of 2 chest drains were placed in the mediastinum and pleura if the internal thoracic artery was harvested. After closure of the chest, continuous suction (5$10 \mathrm{~mm} \mathrm{Hg}$ ) was applied to the drains, which were milked at 30-minute intervals to ensure tube patency. Postoperative blood loss measured as total chest tube drainage was recorded, starting immediately after closure of the chest in the operating theater until the chest drains were removed, providing the drainage was less than $20 \mathrm{~mL} / \mathrm{h}$ for 3 consecutive hours.

On arrival in the intensive care unit (ICU), all patients underwent a routine screening, which included ACT, coagulation profile, and full blood count. Derangements of the coagulation profile were treated by an independent intensivist only in cases of excessive bleeding ( $>150 \mathrm{~mL} / \mathrm{h}$ over 2 consecutive hours), with a specific diagnosis-directed therapy. Elevation of ACT of more than 30 seconds when compared with baseline values was treated with an additional dose of protamine (ie, $25 \mathrm{mg}$ ). Values of prothrombin time (PT), activated partial thromboplastin time (APTT), and international normalized ratio (INR) of more than 1.5 times control values suggested factor deficiency and were corrected by infusion of fresh frozen plasma. A platelet count of less than $80,000 / \mu \mathrm{L}$ was an indication for platelet transfusion. A hematocrit level of less than $24 \%$ was corrected by transfusion of red blood cells. Indications for reopening were a blood loss of greater than $500 \mathrm{~mL}$ over the first hour, greater than $300 \mathrm{~mL}$ for 2 consecutive hours, greater than $200 \mathrm{~mL}$ for 3 consecutive hours, or greater than $1 \mathrm{~L}$ over the first 8 hours.

Clotting profiles and hematologic indices. We also sought to retrospectively review the blood clotting profiles and hematologic indices. Data were obtained as part of the routine clinical monitoring of patients undergoing coronary operations at our institution. These included PT, APTT, activated partial thromboplastin ratio (APTR), INR, platelet 
Table I. Coagulation indices

\begin{tabular}{|c|c|c|}
\hline & On-pump predicted means (median) & Off-pump predicted means (median) \\
\hline \multicolumn{3}{|l|}{$\log _{10}(\mathrm{PT})$} \\
\hline T0 preoperative & $(1.1303)$ & $(1.12)$ \\
\hline $\mathrm{T} 1 \mathrm{~h}$ postoperatively & $1.2645(1.26245)$ & $1.23082(1.23300)$ \\
\hline $\mathrm{T} 212 \mathrm{~h}$ postoperatively & $1.23065(1.22011)$ & $1.19601(1.20683)$ \\
\hline $\mathrm{T} 336 \mathrm{~h}$ postoperatively & $1.19584(1.19312)$ & $1.1612(1.17026)$ \\
\hline $\mathrm{T} 460 \mathrm{~h}$ postoperatively & $1.17965(1.15685)$ & $1.14501(1.11394)$ \\
\hline \multicolumn{3}{|l|}{$\log _{10}($ APTT $)$} \\
\hline T0 preoperative & $(1.49554)$ & $(1.487138)$ \\
\hline $\mathrm{T} 11 \mathrm{~h}$ postoperatively & $1.56678(1.56703)$ & $1.54300(1.55267)$ \\
\hline $\mathrm{T} 212 \mathrm{~h}$ postoperatively & $1.53561(1.52634)$ & $1.51183(1.51720)$ \\
\hline $\mathrm{T} 336 \mathrm{~h}$ postoperatively & $1.50444(1.50379)$ & $1.48065(1.51983)$ \\
\hline $\mathrm{T} 460 \mathrm{~h}$ postoperatively & 1.48994 (1.48996) & $1.46616(1.45788)$ \\
\hline \multicolumn{3}{|l|}{$\log _{\mathrm{e}}(\mathrm{INR})$} \\
\hline T0 preoperative & $(0)$ & $(0)$ \\
\hline $\mathrm{T} 11 \mathrm{~h}$ postoperatively & $0.38714(0.33647)$ & $0.30943(0.33647)$ \\
\hline $\mathrm{T} 212 \mathrm{~h}$ postoperatively & $0.29568(0.26236)$ & $0.21797(0.26236)$ \\
\hline T3 $36 \mathrm{~h}$ postoperatively & $0.20422(0.18232)$ & $0.12651(0.18232)$ \\
\hline $\mathrm{T} 460 \mathrm{~h}$ postoperatively & $0.16170(0.0000)$ & $0.08399(0.0000)$ \\
\hline \multicolumn{3}{|l|}{$\log _{\mathrm{e}}(\mathrm{APTR})$} \\
\hline T0 preoperative & $(0)$ & $(-0.03)$ \\
\hline $\mathrm{T} 11 \mathrm{~h}$ postoperatively & $0.16757(0.15700)$ & $0.11210(0.11333)$ \\
\hline $\mathrm{T} 212 \mathrm{~h}$ postoperatively & $0.10546(0.06766)$ & $0.04999(0.04879)$ \\
\hline T3 $36 \mathrm{~h}$ postoperatively & $0.04335(0.04402)$ & $-0.01211(0.06766)$ \\
\hline $\mathrm{T} 460 \mathrm{~h}$ postoperatively & $0.01448(0.01489)$ & $-0.04099(-0.04082)$ \\
\hline
\end{tabular}

count, hematocrit level, and hemoglobin level. The time of sampling was prospectively defined at baseline and at 1,12 , 36 , and 60 hours postoperatively. To prevent the potential bias by discarding whole patients, those with a missing sample or with a sample drawn out of the predefined time of observation were not excluded from the retrospective analysis.

Laboratory methods. Blood samples were collected from the central venous line at the following times: before induction of anesthesia (T0); on arrival in the ICU (T1); and thereafter at 12, 36, and 60 hours (T2-T4). The blood samples for evaluation of hematologic indices (hemoglobin levels, hematocrit levels, and platelet counts) were drawn into 4-mL vacuum containers containing potassium ethylene diaminetetraacetic acid. Analysis was then carried out on an $\mathrm{H} 2 / \mathrm{H} 3$ Technicon instrument (Bayer A/G, Leverkusen, Germany). A further $4 \mathrm{~mL}$ of blood was drawn into a vacuum container with sodium citrate and was then used to assess the clotting profile (APTT, APTR, PT, and INR) with an ACL analyzer (Instrumentation Laboratories, Inc, Lexington, Mass).

Transfusion costs. The total (intraoperative and postoperative) number of units of red blood cells, fresh frozen plasma, and platelets were recorded for each patient, and cost was calculated from the number of units transfused only.

Sample size. Postoperative stay in our institution for conventional CABG in 1997 was $7.31 \pm 1.6$ days. We considered a clinically meaningful reduction in this period to be 1 day, a reduction of $14 \%$. To detect a clinically meaningful reduction with a probability of 0.9 and choosing a 5\% significance level, it was calculated that 100 patients per group would be required.
Statistical analysis. All collected data were first investigated by using simple tabulations and histograms to establish the distribution of the data. We acknowledge that the sample size depended on the length of postoperative stay being treated as a continuous variable. Investigation of the data revealed that most of the postoperative length of stay values lay in a narrow range and were highly positively skewed. Because these were not found to be continuous and not normally distributed, postoperative length of stay was treated as ordered discrete data, as was intubation time and ICU stay. The data were arranged as contingency tables (cross-tabulations), with the criteria that each cell of the table has an expected frequency of 5 or more (Table I). To test for differences between the on- and off-pump groups, $\chi^{2}$-based tests were used. Data were presented as numbers of patients and cumulative percentages. Because the cells of the table had a natural ordering (eg, 4 days to $\geq 10$ days), $\chi^{2}$ values for trend were first calculated. These were then subtracted from the overall $\chi^{2}$ value to obtain the variation attributable to differences between the 2 groups. ${ }^{14}$

The numbers of transfused units received by each patient were arranged as contingency tables, again with the condition that each cell of the table had an expected frequency of 5 or more. The resulting $2 \times 2$ tables were analyzed with $\chi^{2}$ tests. Other preoperative and postoperative variables having binary outcomes were analyzed in a similar fashion.

Chest tube drainage data were found to be positively skewed. To calculate $95 \%$ confidence intervals (CIs) for these data, it was found that a $\log _{10}$ approximation to the normal distribution was appropriate. 


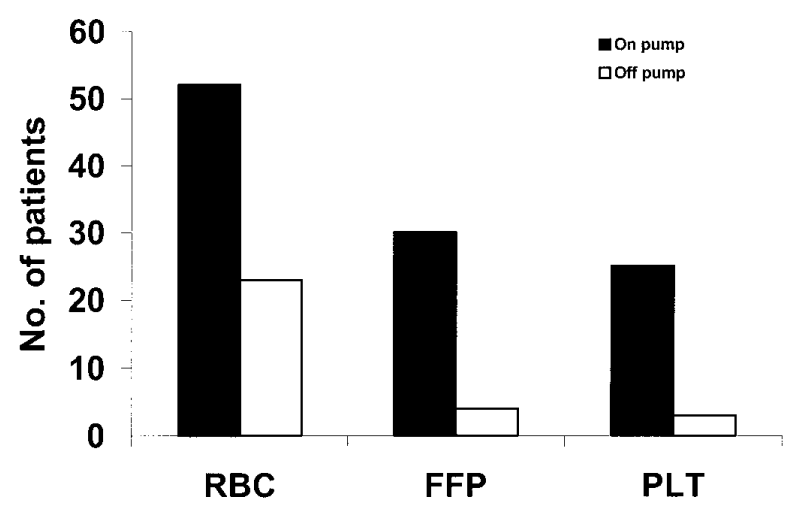

Fig 1. Number of patients receiving red blood cells $(R B C)$, fresh frozen plasma $(F F P)$, and platelets $(P L T)$.

To analyze the hematologic and coagulation indices, a mixed linear model was proposed by using Proc Mixed in the SAS software (SAS Institute, Inc, Cary, NC). This was used to calculate predicted mean values for the time points of each of the variables. The Residual Maximum Likelihood (REML) method was used to perform the analysis because it is considered to have benefits when dealing with data that have missing values. ${ }^{14}$ Because time points were unequally spaced, time was first transformed by using a log transformation to make the intervals as equal as possible. The effect of bypass, preoperative measurement, and time were considered as fixed effects. A random intercept and coefficient for time was fitted, and the patients were fitted as a random effect. The fixed effects were noted and used to generate a prediction line for the hematologic variables. The medians were included in these plots to establish the suitability of the model fitted. CIs were not calculated because it was considered that the missing data may provide misleading results. ${ }^{14}$

Transfusion-related costs are presented as means \pm SEM. Comparison between the groups was performed by using the unpaired $t$ test.

\section{Results}

The randomization sequence was strictly respected. Two patients allocated to the off-pump group crossed over to the on-pump group right at the beginning of the operation because hemodynamically their heart did not tolerate the surgical maneuvers to expose the target anastomotic site. These 2 patients were included in the off-pump group for the intention-to-treat analysis.

The groups were similar in terms of age, body surface area, sex ratio, diabetes mellitus, extent of coronary disease, left ventricular function, number of grafts per patient, and graft distribution. Thirty-seven patients in the on-pump group and 35 in the off-pump group were in-hospital referrals with unstable angina still receiving

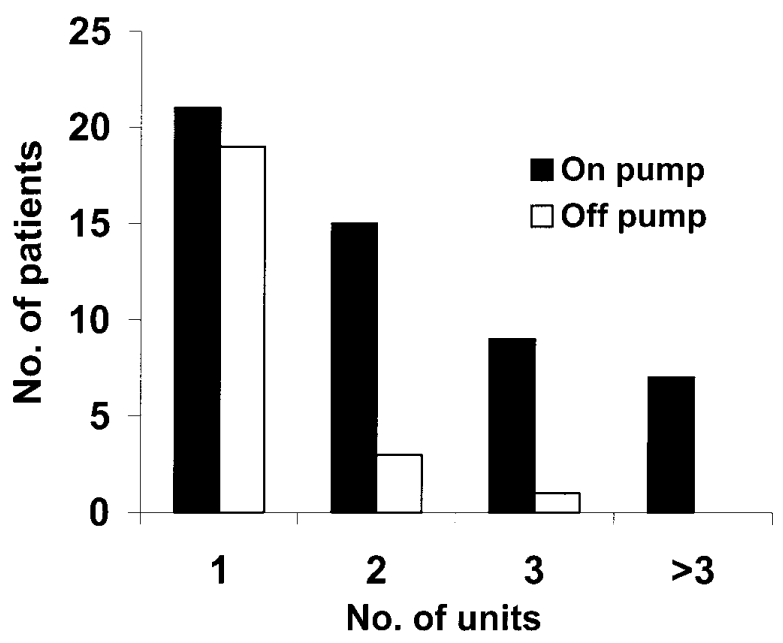

Fig 2. Number of patients receiving 1 or more units of red blood cells.

aspirin and low-molecular-weight heparin. The remaining stable patients were elective admissions from home in whom the aspirin had been stopped 4 days before the operation. Distribution of preoperative and intraoperative characteristics and the overall clinical outcome of the 2 groups have been previously reported. ${ }^{11}$ Chest tube drainage, transfusion requirement, and related complications are reported in Table II.

Postoperative length of stay was found to be significantly different at $8 \%$. Further interpretation of data, however, revealed that $75 \%$ of patients in the off-pump group were discharged 6 days postoperatively compared with $50 \%$ in the on-pump group. After 7 days, only 15 patients in the off-pump group remained in the hospital compared with 29 patients in the on-pump group.

A significant difference in the number of patients requiring more than 1 day in the ICU was also observed, with the percentage of off-pump patients leaving the ICU 1 day after the operation being 97\% compared with $75 \%$ for the on-pump group.

Because chest tube drainage was best approximated to the normal distribution by a $\log _{10}$ transformation, a comparison of the 2 groups was described by calculating a mean ratio of chest tube drainage and a $95 \% \mathrm{CI}$. This was done by finding the antilog of ( $\log _{10}$ on-pump - $\log _{10}$ off-pump) and was calculated to be 1.64 (95\% CI, 1.39-1.94). The chest tube drainage was on average 1.6 times higher in the on-pump compared with that of the off-pump group. This larger loss of blood is also reflected in the use of transfusion units (Figs 1 and 2). The transfusion requirements of the 2 groups were significantly different when measured by "required" and 
Table II. Chest tube drainage, transfusion, and reopening for bleeding

\begin{tabular}{|c|c|c|c|}
\hline Variable & On-pump group $(n=100)$ & Off-pump group $(n=100)$ & $\mathrm{P}$ value \\
\hline \multicolumn{4}{|l|}{ Total blood loss (mL) } \\
\hline Mean $(95 \% \mathrm{CI})$ & $943.19(844-1054)$ & $687(624-756)$ & $<.05$ \\
\hline \multicolumn{4}{|l|}{ Transfusion requirement } \\
\hline \multicolumn{4}{|l|}{ RBC units } \\
\hline 0 & 48 & 77 & $<.05$ \\
\hline$\geq 1$ & 52 & 23 & \\
\hline \multicolumn{4}{|l|}{ FFP units } \\
\hline 0 & 70 & 96 & $<.05$ \\
\hline$\geq 1$ & 30 & 4 & \\
\hline \multicolumn{4}{|l|}{ Platelet units } \\
\hline 0 & 75 & 97 & $<.05$ \\
\hline$\geq 1$ & 25 & 3 & \\
\hline Total reopening (n) & 8 & 2 & $.05<P<.1$ \\
\hline Revision for ischemia & 1 & 0 & - \\
\hline Bleeding with obvious point & 2 & 2 & - \\
\hline Bleeding with no obvious point & 5 & 0 & - \\
\hline
\end{tabular}

$C I$, Confidence intervals; $R B C$, red blood cells; $F F P$, fresh frozen plasma.

"did not require" criteria. In the off-pump group less than $5 \%$ of patients required FFP and platelet units, whereas in the on-pump group it was $30 \%$ and $25 \%$, respectively (Table II).

The significant difference in transfusion requirement also reflected in the related costs attributable to each group (mean transfusion cost per patient, $\$ 184.8 \pm$ $\$ 35.2$ and $\$ 21.47 \pm \$ 6.9$ in the on-pump and off-pump groups, respectively; $P<.01)$.

In the on-pump group 7 patients were reoperated on for bleeding. However, a surgical bleeding point was identified in only 2 of these patients, a thoracic artery bed branch in 1 patient and an atrial cannulation site in the second patient. In the remaining 5 patients diffuse bleeding with no obvious surgical cause was found. In the off-pump group, 2 patients were reoperated on, 1 for a side branch of the thoracic artery and the second for a side branch of a venous graft (Table II).

The coagulation indices were also found to differ between the 2 groups (Table I). The predicted $\log _{10}$ (APTT) was lower in the off-pump group. The observed median values were also lower in the offpump group, with the exception of 36 hours postoperatively. A similar result was observed for the $\log _{\mathrm{e}}$ (APTT ratio). For both $\log _{\mathrm{e}}(\mathrm{INR})$ and $\log _{10}(\mathrm{PT})$, the predicted values and observed medians were lower in the offpump group.

Having generated the predicted values of hemoglobin levels, hematocrit levels, and platelet counts, these were plotted over time, and the observed median values were added (Fig 3, A-C). Although the 2 plots showed a similar trend, it is noticeable that the off-pump group would appear to have higher predicted values and observed medians at any observation point when compared with the on-pump group.

\section{Discussion}

Patients undergoing cardiac operations with CPB are at increased risk of perioperative blood loss requiring transfusion of blood products. ${ }^{15}$ The contact activation with the extracorporeal circuit, shear forces, activation of the complement system, fibrinolysis, and extrinsic factors, such as medications, all contribute to platelet dysfunction, which may result in increased postoperative bleeding. ${ }^{1,16,17}$ The need to decrease the incidence of postoperative bleeding and related complications has led to the development of strategies, such as the use of cell salvage devices to recirculate nonheparinized blood and the routine use in some instances of drugs, such as aprotinin or tranexamic acid. ${ }^{18,19}$

Recently, there has been a suggestion that by performing coronary revascularization on the beating heart, there may be a reduction of blood loss..$^{7-10,20}$ However, no randomized study has assessed the influence of beating-heart coronary operations on both blood loss and transfusion requirement.

This study shows a significant decrease in postoperative blood loss measured as total chest tube drainage and transfusion requirement with beating-heart operations when compared with conventional CABG with CPB. Although the blood loss seems slightly high in the on-pump group of our study, these losses are in keeping with other recently published data. ${ }^{7,21}$ Furthermore, cell salvage devices and the routine use 

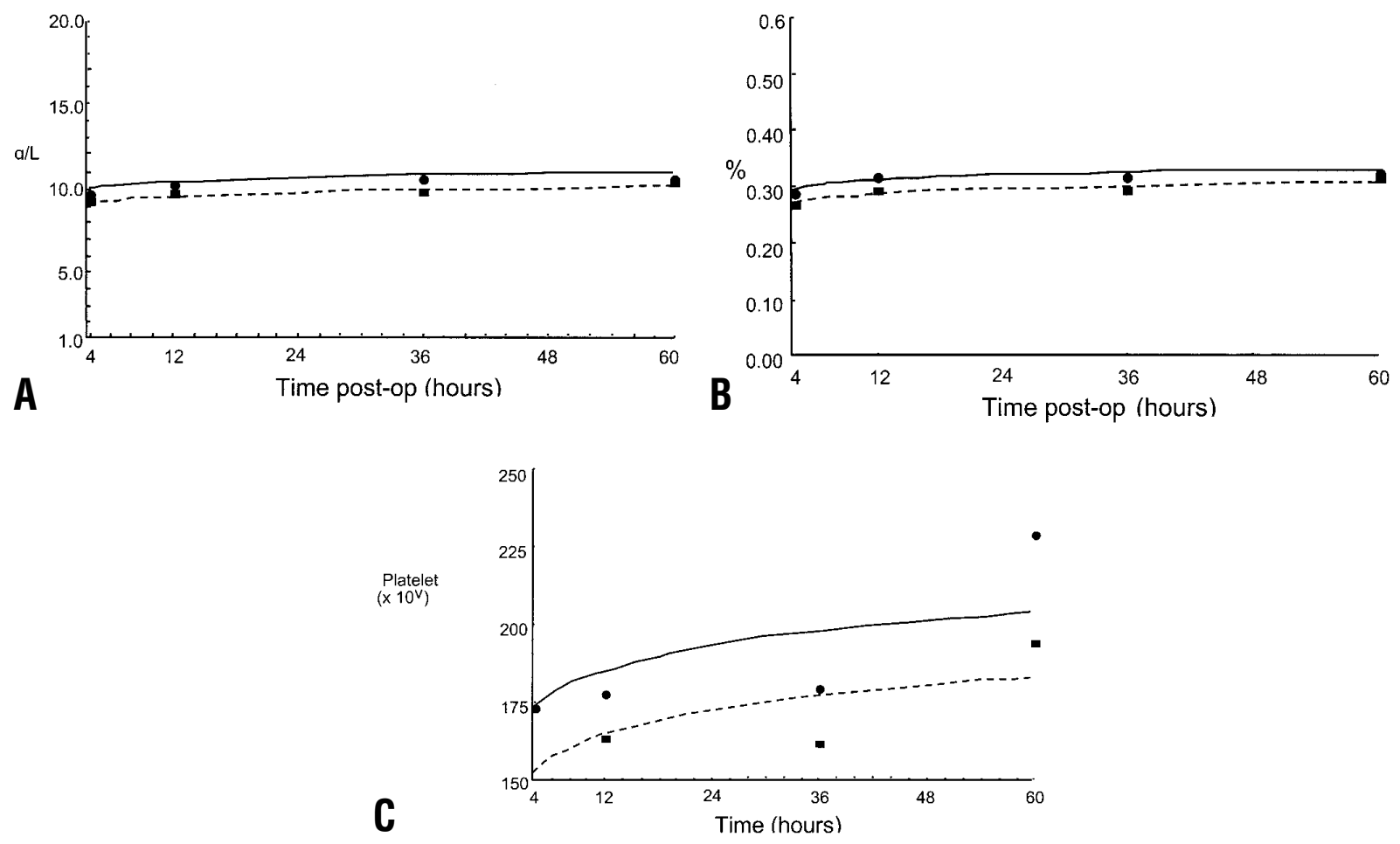

Fig 3. Predicted values (continuous line in the off-pump and dashed line in the on-pump group) and observed medians (circles, off-pump group; squares, on-pump group) over time between on- and off-pump operations for hemoglobin level (A), hematocrit level (B), and platelet count (C).

of tranexamic acid or aprotinin were not used in this study. In addition, $37 \%$ of the patients in the on-pump group and $35 \%$ in the off-pump group were unstable inhospital referrals managed preoperatively with aspirin and low-molecular-weight heparin, which have been reported to increase perioperative blood loss. ${ }^{22}$

One of the first effects of excessive bleeding is the fall in hemoglobin and hematocrit levels. In the present study hemoglobin and hematocrit levels decreased more over time in the on-pump group despite this group requiring a significantly higher transfusion of red blood cells during the postoperative period.

The fall in the blood hemoglobin level observed at the end of the operation in the off-pump group might be related to intraoperative blood loss. However, the effects of hemodilution have to be considered because the infusion of colloid or crystalloid solutions is required during off-pump coronary operations to maintain the mean systemic pressure at greater than $60 \mathrm{~mm}$ $\mathrm{Hg}$, particularly during the construction of the distal anastomoses.

The explanation for the reduced postoperative blood loss observed in the off-pump group is certainly multifactorial. Thrombocytopenia and its relation to postop- erative bleeding are well documented in association with CPB. ${ }^{23}$ Holloway and colleagues ${ }^{5}$ found that the decrease in platelet count during CPB was in excess of that accounted for by hemodilution for priming the extracorporeal circuit. In this study, platelet counts in the on-pump group show the typical time course previously reported during and after operations with CPB. ${ }^{2}$ The greater reduction of platelet counts throughout the study observed in the on-pump group suggests a depletion caused by contact activation with extracorporeal surfaces, bubble oxygenator, cardiotomy suction, and filters. ${ }^{23}$ However, the decrease of platelet counts in the on-pump group was rarely less than the value $(50,000-100,000 / \mu \mathrm{L})$ normally required for hemostasis, suggesting a degree of impaired platelet function. Platelet dysfunction with the loss of aggregability is largely reported as a cause of bleeding after CPB..$^{24,25}$ The absence of platelet function evaluation rather than count alone is, however, a limitation of this work.

The INR as calculated from and directly proportional to the PT is a test of the extrinsic system and final common pathway of coagulation. Clotting factor deficiencies or circulating anticoagulants will therefore 
increase this ratio. The raised INR after CPB is reported to increase both chest tube drainage and the quantity of hemostatic blood products transfused. ${ }^{22}$ The current study also shows a higher increase over time of all clotting screen times in the on-pump group, suggesting an alteration of the hemostatic system.

A limitation of this study is that the analysis of coagulation and hematologic indices was not included in the original study design. However, the time of observation was prospectively defined, and data were obtained as part of the routine continuous clinical monitoring of patients undergoing coronary operations at our institution.

As might be expected from the higher chest tube drainage, we have also shown a significantly greater transfusion requirement in the on-pump group. It is worth noting that less than one quarter of the patients in the off-pump group required transfusion compared with over half of the patients in the on-pump group. This finding might lead to transfusion-related complications. ${ }^{26,27}$

The current era of health care has placed higher emphasis on curtailment of costs and resources while maintaining quality of care and patient satisfaction. As such, the reduction of cost related to less transfusion requirement observed in the off-pump group may clearly compare with other reported strategies of cost containment, ${ }^{6}$ while avoiding the detrimental effect of CPB.

In conclusion, this study shows that beating-heart coronary operations are associated with a significant reduction in postoperative bleeding and transfusion requirement when compared with conventional operation with $\mathrm{CPB}$ and cardioplegic arrest. Given that nearly $10 \%$ of the 3.2 million annual recipients of red blood cell transfusions in the United States are patients undergoing $\mathrm{CABG},{ }^{28}$ the routine implementation of the off-pump coronary operation should have significant implications in terms of reducing cost and postoperative complications related to blood-product transfusion.

We thank Jennifer A. White, MS, of the Department of Biostatistics and Epidemiology, at the Cliveland Clinic Foundation.

Received for publication Nov 12, 1999; revisions requested Feb 7, 2000; revisions received Aug 24, 2000; accepted for publication Oct 12, 2000.

Address for reprints: Gianni D. Angelini, FRCS, Bristol Heart Institute, Bristol Royal Infirmary, Bristol BS2 8HW, United Kingdom (E-mail: G.D.Angelini@bristol.ac.uk).

\section{REFERENCES}

1. Kawahito K, Kobayashi E, Iwasa H, Misawa Y, Fuse K. Platelet aggregation during cardiopulmonary bypass evaluated by a laser light-scattering method. Ann Thorac Surg 1999;67:79-84.

2. Consten ECJ, Henny CP, Eijsman L, Dongelmans DA, van Oers MHJ. The routine use of fresh frozen plasma in operations with cardiopulmonary bypass is not justified. $\mathrm{J}$ Thorac Cardiovasc Surg 1996;112:162-7.

3. Asimakopoulos G, Taylor KM. Effects of cardiopulmonary bypass on leukocyte and endothelial adhesion molecules. Ann Thorac Surg 1998;66:2135-44.

4. Liu B, Belboul A, Larsson S, Roberts D. Factors influencing haemostasis and blood transfusion in cardiac surgery. Perfusion 1996;11:131-43.

5. Holloway DS, Summaria L, Sandesara J, Vagher JP, Alexander JC, Caprini JA. Decreased platelet number and function and increased fibrinolysis contribute to postoperative bleeding in cardiopulmonary bypass patients. Thromb Haemost 1988;59:62-7.

6. Birkmeyer JD, AuBuchon JP, Littenberg B, et al. Cost-effectiveness of preoperative autologous donation in coronary artery bypass grafting. Ann Thorac Surg 1994;57:161-9.

7. Bouchard D, Cartier R. Off-pump revascularization of multivessel coronary artery disease has a decreased myocardial infarction rate. Eur J Cardiothorac Surg 1998;14(Suppl 1):S20-4.

8. Ascione R, Lloyd CT, Gomes WJ, Caputo M, Bryan AJ, Angelini GD. Beating versus arrested heart revascularization: evaluation of myocardial function in a prospective randomised study. Eur $\mathbf{J}$ Cardiothorac Surg 1999;15:685-90.

9. Ascione R, Lloyd CT, Underwood MJ, Gomes WJ, GD Angelini. On pump versus off pump coronary revascularization: evaluation of renal function. Ann Thorac Surg 1999;68:493-8.

10. Brasil LA, Gomes WJ, Salomao R, Buffalo E. Inflammatory response after myocardial revascularization with or without cardiopulmonary bypass. Ann Thorac Surg 1998;66:56-9.

11. Ascione R, Lloyd CT, Underwood MJ, Lotto AA, Pitsis AA, Angelini GD. Economic outcome of off pump coronary artery bypass surgery in a prospective randomised study. Ann Thorac Surg 1999:68:2237-42.

12. Caputo M, Dihmis W, Bryan AJ, Suleiman MS, Angelini GD. The effect of magnesium on myocardial metabolism during ischemia and reperfusion, in patients undergoing coronary artery surgery using intermittent antegrade warm blood cardioplegia. Eur J Cardiothorac Surg 1998;14:596-601.

13. Pitsis AA, Angelini GD. Off-pump coronary bypass grafting of the circumflex artery. Eur J Cardiothorac Surg 1999;16:478-9.

14. Brown HK, Kempton RA. The application of REML in clinical trials. Stat Med 1994;13:1601-17.

15. Despotis GJ, Joist JH, Goodnough LT. Monitoring of hemostasis in cardiac surgical patients: impact of point-of-care testing on blood loss and transfusion outcomes. Clin Chem 1997;43: 1684-96.

16. Kestin AS, Valeri CR, Khuri SF, et al. The platelet function defect of cardiopulmonary bypass. Blood 1993;82:107-17.

17. Khuri SF, Valeri CR, Loscalzo J, et al. Heparin causes platelet dysfunction and induces fibrinolysis before cardiopulmonary bypass. Ann Thorac Surg 1995;60:1008-14.

18. Baufreton C, Jansen PG, Le Besnerais P, et al. Heparin coating with aprotinin reduces blood activation during coronary artery operations. Ann Thorac Surg 1997;63:50-6. 
19. Karski JM, Teasdale SJ, Norman P, et al. Prevention of bleeding after cardiopulmonary bypass with high-dose tranexamic acid. Double-blind, randomized clinical trial. J Thorac Cardiovasc Surg 1995;110:835-42.

20. Poirier NC, Carrier M, Lesperance J, et al. Quantitative angiographic assessment of coronary anastomoses performed without cardiopulmonary bypass. J Thorac Cardiovasc Surg 1999;117:292-7.

21. Lemmer JH, Dilling EW, Morton JR, et al. Aprotinin for primary coronary artery bypass grafting: a multicenter trial of three dose regimens. Ann Thorac Surg 1996;62:1659-67.

22. Despotis GJ, Filos KS, Zoys TN, Hogue CW Jr, Spitznagel E, Lappas DG. Factors associated with excessive postoperative blood loss and hemostatic transfusion requirements: a multivariate analysis in cardiac surgical patients. Anesth Analg 1996;82:13-21.
23. Weerasinghe A, Taylor KM. The platelet in cardiopulmonary bypass. Ann Thorac Surg 1998;66:2145-52.

24. Oberman HA. Indications and monitoring of use of fresh frozen plasma as a haemostatic agent. Curr Stud Hematol Blood Transfus 1986;53:125-32.

25. Spiess BD. The contribution of fibrinolysis to post bypass bleeding. J Cardiothorac Vasc Anesth 1991;5:13-7.

26. Zacharias A, Habib RH. Factors predisposing to median sternotomy complications. Deep vs superficial infections. Chest 1996;110:1173-8.

27. Moor AC, Dubbelman TM, Van Steveninck J, Braud A. Transfusion-transmitted diseases: risks, prevention and perspectives. Eur J Haematol 1999;62:1-18.

28. Goodnough LT, Johnston MFM, Toy PTCY, et al. The variability of transfusion practice in coronary artery bypass surgery. JAMA 1991;265:86-90

\section{Availability of Journal back issues}

As a service to our subscribers, copies of back issues of The Journal of Thoracic and Cardiovascular Surgery for the preceding 5 years are maintained and are available for purchase from Mosby until inventory is depleted. The following quantity discounts are available: $25 \%$ off on quantities of 12 to 23, and one third off on quantities of 24 or more. Please write to Mosby, Subscription Customer Service, 6277 Sea Harbor Dr, Orlando, FL 32877, or call 800-654-2452 or 407-345-4000 for information on availability of particular issues and prices. If unavailable from the publisher, photocopies of complete issues may be purchased from Bell \& Howell Information and Learning, 300 N Zeeb Rd, Ann Arbor, MI 48106-1346; 734-761-4700 or 800-521-0600. 